(US\$900 million) to $£ 720$ million in 1993 to try to maintain its success in developing such popular drugs as its anti-ulcer medicine Zantac. And while most of Japanese industry has held down R\&D spending, Japan's drug industry increased its spending on $R \& D$ in 1992 by 6 per cent, a rate well above inflation. Similarly, in the United States and Switzerland drug companies are maintaining heavy investment in drug development, exceeding 10 per cent of sales.

Another glimmer of hope is offered by the election of Bill Clinton as US president. Many observers expect Clinton to strengthen government support of industrial research, much as the Ministry of International Trade and Industry does in Japan. But any such policies are unlikely to have much effect on spending during 1993.

David Swinbanks

\section{Agricultural biotech moves into spotlight}

The year is likely to be the most critical yet for the agricultural biotechnology industry. This summer, all eyes will be on Calgene, Inc. of Davis, California, as it introduces its rot-resistant Flavr Savr tomato into the \$3.5billion annual US market. A successful launch will also pave the way for the next wave of genetically engineered foods and make it easier for agricultural biotechnology companies to raise capital.

Roger Salquist, Calgene's chairman and chief executive officer, has become the industry's standard bearer in building consumer confidence in genetically engineered foods and doing battle with critics. A frequent foe is Jeremy Rifkin of the Washington-based Foundation on Economic Trends, who agrees that this year will also be critical for the foundation. He has promised to step up his 'Pure Food Campaign', and to lead a boycott of each new genetically engineered food until regulators implement pre-market testing and labelling of the foods.

All Calgene has actually done with its Flavr Savr tomato is to isolate the gene that codes for the polygalacturonase enzyme and reintroduce it into selected tomato varieties in the reverse or 'antisense' orientation. That change blocks the action of the enzyme, which causes softening of the fruit, by as much as 99 per cent, producing a better-tasting, longer-lasting tomato that can be harvested from the vine when ripe instead of ripening artificially. If Calgene's tomato is rejected by consumers, predicts Louis $\mathrm{Da}$ Gama, executive director of the UK Biolndustry Association (BIA), the idea of introducing novel genes into crop plants "will be dead in the water".

The Flavr Savr tomato is expected to be followed within a year by crops able to tolerate herbicide treatments, and within two to three years by crops resistant to insect attack. Eventually, companies hope to develop families of genetically modified oils and fatty acids for use as foodstuffs and in industrial applications as biodegradable lubricants and hydraulic fluids.

At the same time, there is little reason for optimism among those working on novel animal technologies. Genetically engineered bovine somatotropin (BST), when injected into lactating dairy cows, can boost milk yields by 10 per cent or more but offers no benefit to consumers. Despite a clean bill of

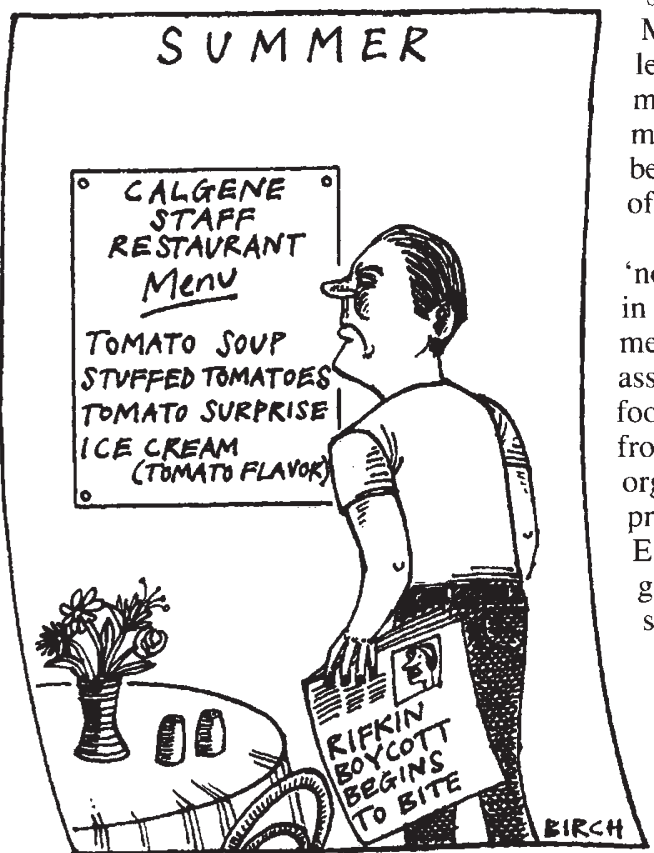

health from several review panels, the drug has become a prime target for consumer lobbyists who have raised questions about its safety and who say that it will put small farmers out of business.

Some expect a smoother regulatory ride in the United States for genetically engineered porcine somatotropin, which when given to pigs produces leaner meat. Philip Paxman, chairman of the European Trade Association for Advanced Animal Breeding, points out that a more efficient, more profitable animal is not enough. "There also has to be a social benefit", he says, such as the use of animals to produce human therapeutics or as model systems to study human disease.

Early this year, the European Commission (EC) is expected to start a significant research initiative in agricultural biotechnology involving more than 50 research laboratories. Managed jointly by the John Innes Centre in Norwich, England, and the Max Planck Institute for Breeding Research in Cologne, Germany, and funded initially for three years, the programme is intended to strengthen the European science base and make it a stronger international competitor. Richard Flavell, director of the John Innes Centre, says that the programme will try "to create a platform of research right across Europe that is seamless and that will give rise to discoveries, trained people and information that will be particularly useful to European industry". It is expected to cover research into plant development, with emphasis on hormones and related growth substances, in addition to environmentally friendly agricultural research, research to improve the quality of harvested products and the use of beneficial microorganisms.

Despite positive news last year for the agricultural biotechnology industry in the United States, a patchwork of regulations still exists in Europe. The Council of Ministers' directive on the deliberate release into the environment of genetically modified organisms, due to be adopted by member states in October 1991, has yet to be implemented by six of the 12 countries of the European Communities.

There is some progress expected on the 'novel foods' regulation, under discussion in the Council and in the European Parliament. The regulation sets out a means of assessing the safety of all novel foods and food ingredients, including those produced from or containing genetically modified organisms. The BIA opposes the current proposal, believing that it would place European industry at a disadvantage by going beyond international standards on safety, efficacy and quality.

Legislation is also under discussion in the EC for the labelling of foods produced by genetic modification. Last May, the US Food and Drug Administration gave preliminary approval to eliminating pre-market review and labelling of foods derived from biotech nology except in circumstances where levels of a naturally occurring toxicant have been increased, when an allergen not usually found in a plant has been introduced and where levels of important nutrients have been changed (see Nature 357, 352; 1992).

Diane Gershon

\section{Magnetic fusion proceeds with no end in sight}

The inauguration of the Tokamak Fusion Test Reactor (TFTR) at Princeton University on Christmas Eve 1982 was described by the world media as the dawn of the era of fusion energy. Almost exactly a decade later - and 35 years after Sir John Cockcroft said (mistakenly) that he was "99 per cent certain" fusion had been demonstrated at Britain's Harwell laboratory - clean, commercially available energy remains a long-term dream.

This year, for reasons both scientific and political, fusion is again likely to make headlines. On the experimental front, two events stand out: the Joint European Torus (JET) at Culham, England, is expected to reopen in October after being closed for 
upgrading, the same month that the TFTR plans to start its own experiments with tritium - the basic fuel for a commercial fusion reactor.

The main purpose of the JET modifications is to study ways of reducing the impact of impurities caused by interaction between the burning plasma and the wall of the tokamak. Such impurities seriously limit the length of ignition; their effects are expected to be reduced by the insertion of a pumped divertor, which traps the impurities by modifying the shape of the magnetic field at the plasma edge and allows them to be removed by a cryopump.

When the divertor studies will be completed by the end of 1994, JET will enter its final stage of full-power operation with deuterium-tritium plasma. Before that happens, however, the spotlight will have been turned back to Princeton's TFTR, where scientists hope to study for the first time the heating effects of alpha particles on the plasma contained by the magnetic field inside the tokamak. Equally important in political terms is the fact that the tritium experiments will allow the TFTR to reach power levels of 5-10 MW, surpassing the 2 megawatts achieved in 1991 by JET using 11-per-cent tritium injected into the deuterium plasma.

The experiments at JET and Princeton will provide results for what is most likely to be the next major goal for the fusion community, namely the construction of the \$6billion International Thermonuclear Experimental Reactor (ITER). Progress on ITER has been slow but steady. The formal agreement setting the framework for cooperation was signed last summer in Washington by the four international partners (the United States, the European Communities, the Russian Federation and Japan). The next twelve months should see a continuation of the design engineering work and the building up of research teams at the three design centres at San Diego in California, Garching in Germany and Naka in Japan (see Nature 360, 615; 1992).

\section{Halfway measures}

Banking on possible delays to ITER, a number of national initiatives have been put forward as intermediate steps. In the United States, the political focus will be on a proposal from Princeton to build a new Tokamak Plasma Experiment (TPX), a $\$ 500$-million project which, if approved, would begin operation around 2003 (see Nature 356, 96; 1992). It would succeed the TFTR, which will be closed in 1994 because of the radioactivity caused by the use of tritium in the forthcoming series of experiments. After winning the backing of the US Department of Energy under the Bush administration, its fate now lies in the hands of President-elect Bill Clinton and his vice-president, $\mathrm{Al}$ Gore.

Across the Pacific, more discreet lobbying efforts are under way to persuade the Japanese government to follow up the

successful operation of its own fusion machine, JT-60, with a new steady-state tokamak. It is also seen as a stepping-stone to ITER. In Europe, as the main political focus shifts from JET to ITER, pressure is also likely to mount for funding for an alternative advanced machine, namely a stellarator, which physicists would like to build at the Institute for Plasma Physics in Garching.

Newspaper headlines in Europe, however, are likely to concentrate on a more pressing question, namely how to handle the consequences for scientists of the eventual closing of JET. The issue is of particular concern to British staff who, unlike colleagues from other European states, work under contract to the British AEA Technology, rather than to Euratom.

\section{Networks enhance use of computers}

Scientists can be expected to continue finding new ways to take advantage of improvements in the scope and speed of high-performance computers. As computing power becomes more crucial to national and regional economic security, two areas attracting the most attention are massively parallel processing, in which thousands of individual processors perform millions of tasks simultaneously rather than sequentially, and the linking of highperformance computers to networks.

The European Communities (EC) are being urged to begin a decade-long high-performance computing research programme using public and private funds amounting to ECU1 billion (US $\$ 1.25$ billion) a year. Part of the sales pitch, outlined in an October report by a European Commission panel led by CERN's Carlo Rubbia, is that there exists a "unique window of opportunity" for Europe to invent new hardware and software applications for the latest breed of massively parallel high-speed computers. The current research and development programmes, ESPRIT and RACE, have pushed the technology ahead and produced startup companies, but the report laments that larger companies from outside Europe often are quicker to exploit the markets created by new technologies (as Fujitsu Ltd hopes to do in acquiring the British computer maker ICL).

The name that Japan has given to its high-performance computing initiative - the Real World Computing project reflects an emphasis on applicationsorientated research, as well as a step back from the lofty goals of its less-thansuccessful predecessor, the now cancelled Fifth Generation project on artificial intelligence. Meanwhile, Fujitsu will attempt to move ahead of the pack with what promises to be the fastest supercomputer yet.

In the United States, which leads the world in massively parallel processing and
A report commissioned by the Commission at the prompting of the European Parliament has recommended that British scientists be given the same contractual status as their European colleagues (see Nature 357, 270; 1992). But this will cost money, and implies a long-term commitment that the British government has so far not been willing to make.

The JET council meets in March to discuss its next move. Without a shift in Britain's position, the council is unlikely to be in a position to recommend a solution to the dispute. Union representatives are already warning that such an outcome could lead to a renewal of last summer's strikes. This looming dispute suggests that fusion may generate some heat this year, even if not the type originally intended. David Dickson

semiconductor research, the new Clinton administration is preparing to launch the second phase of a High-Performance Computing and Communications project to provide new supercomputer applications for health care, education and manufacturing. A key component on the project, launched in 1991, is the five-year effort to create a National Research and Educational Network using optical fibre cables to connect universities, major research centres, industry and possibly even homes.

Towards that end, the US Department of Energy and American Telephone and Telegraph $\mathrm{Co}$. are improving the speed of such a network. One test scheduled for this summer will involve researchers using two Cray supercomputers to link 30 computers capable of transmitting 1 billion bits of information. That would be equal to sending 100 novels every second. The speed of the US Internet databank system will also be improved in 1993, from 1.5 million bits per second to a consistent 45 million bits per second, with laboratory tests in the mid-100 million to one-gigabit range.

\section{Greater efficiency}

Research into the field of high-performance computing will continue to focus on making supercomputers faster, but an equal challenge will be to make them work more efficiently. A central goal is rapid transmittal of massive amounts of data in the form of moving video. The supercomputers seem up to the task, but technical problems inhibit networks from carrying such vast amounts of data. Optical fibre network switches so far are unable to detect and correct transmission errors at such high speeds. Regulatory logjams also plague the network in the United States, as telephone companies lack government permission to charge rate tariffs sufficient to cover the costs of transmitting large volumes of high-speed data.

In the realm of parallel processing, 